\title{
Length and height percentiles for children in the South-East Asian Nutrition Surveys (SEANUTS)
}

\author{
Nipa Rojroongwasinkul 1,*, Khanh Le Nguyen Bao ${ }^{2}$, Sandjaja Sandjaja ${ }^{3}$, Bee Koon Poh ${ }^{4}$, \\ Atitada Boonpraderm ${ }^{1}$, Chinh Nguyen Huv ${ }^{2}$, Moesijanti Soekatri ${ }^{3}$, Jyh Eiin Wong ${ }^{4}$, \\ Paul Deurenberg ${ }^{5}$ and Yannis Manios ${ }^{6}$ on behalf of the SEANUTS Study Group \\ ${ }^{1}$ Institute of Nutrition, Mahidol University, Nakhon Pathom 73170, Thailand: ${ }^{2}$ Department of Occupational and \\ School Nutrition, National Institute of Nutrition (NIN), Hanoi, Vietnam: ${ }^{3}$ Persatuan Ahli Gizi Indonesia, Jakarta, \\ Indonesia: ${ }^{4}$ Nutritional Sciences Programme, School of Healthcare Sciences, Faculty of Health Sciences, Universiti \\ Kebangsaan Malaysia, Kuala Lumpur, Malaysia: ${ }^{5}$ Nutrition Consultant, Telaga Harbour Marina, Langkawi, \\ Malaysia: ${ }^{6}$ Department of Nutrition and Dietetics, Harokopio University, Athens, Greece
}

Submitted 30 January 2015: Final revision received 30 September 2015: Accepted 20 October 2015: First published online 24 November 2015

\begin{abstract}
Objective: Health and nutritional information for many countries in the South-East Asian region is either lacking or no longer up to date. The present study aimed to calculate length/height percentile values for the South-East Asian Nutrition Survey (SEANUTS) populations aged 0.5-12 years, examine the appropriateness of pooling SEANUTS data for calculating common length/height percentile values for all SEANUTS countries and whether these values differ from the WHO growth references.

Design: Data on length/height-for-age percentile values were collected. The LMS method was used for calculating smoothened percentile values. Standardized site effects (SSE) were used for identifying large or unacceptable differences (i.e. $|\mathrm{SSE}|>0.5$ ) between the pooled SEANUTS sample (including all countries) and the remaining pooled SEANUTS samples (including three countries) after weighting sample sizes and excluding one single country each time, as well as with WHO growth references.

Setting: Malaysia, Thailand, Vietnam and Indonesia.

Subjects: Data from 14202 eligible children were used.

Results: From pair-wise comparisons of percentile values between the pooled SEANUTS sample and the remaining pooled SEANUTS samples, the vast majority of differences were acceptable (i.e. $|\mathrm{SSE}| \leq 0.5$ ). In contrast, pair-wise comparisons of percentile values between the pooled SEANUTS sample and WHO revealed large differences.

Conclusions: The current study calculated length/height percentile values for South East Asian children aged 0.5-12 years and supported the appropriateness of using pooled SEANUTS length/height percentile values for assessing children's growth instead of country-specific ones. Pooled SEANUTS percentile values were found to differ from the WHO growth references and therefore this should be kept in mind when using WHO growth curves to assess length/height in these populations.
\end{abstract}

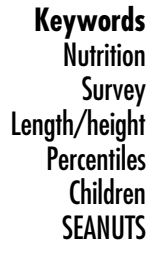

The economic transition due to rapid industrialization observed over the last decades in South-East Asian countries has coincided with marked changes in dietary habits and lifestyle patterns that may have a significant impact on several health indices in these populations ${ }^{(1-4)}$. Because of these lifestyle changes, growth and physical development in infants, children and adolescents can be influenced and this is reflected mainly in changes recorded over time in certain anthropometric indicators, namely body weight, stature (or recumbent length in infants) and BMI. In this context, according to data from the $\mathrm{WHO}^{(5,6)}$, the decreasing trend in the prevalence of stunting (by 43.4 million) and underweight (by 35.6 million) and the increasing prevalence of overweight and obesity (by 4.4 million) observed over the last two decades among children in South-East Asia (including Thailand, Indonesia and Malaysia) provide a strong indication of this impact. 
The assessment of growth, health and nutritional status in infants, children and adolescents relies mainly on the use of growth reference percentile values and standards. In 2006, WHO published new growth standards for infants and children from birth to 5 years of age ${ }^{(7)}$. For the development of these new growth standards the WHO Multicentre Growth Reference Study (MGRS) was conducted between 1997 and 2003 to collect anthropometric data in Brazil, Ghana, India, Norway, Oman and the USA. Furthermore, in 2007 the WHO released growth standards for children and adolescents from 5 to 19 years of age, which were based on the reconstruction of the 1977 National Center for Health Statistics/WHO growth reference values $^{(8)}$. However, certain studies report deviations of mean anthropometric indices compared with the WHO reference in healthy Asian child populations ${ }^{(\vartheta, 10)}$. Relevant discrepancies derived from comparisons with the WHO growth reference values have also been reported for more prosperous South Asian (Indian) children living in the Netherlands ${ }^{(11,12)}$, thus raising questions regarding the general applicability of the WHO reference as an international growth standard. Although WHO growth references are intended for international use, variations in the genetic backgrounds and environmental influences among different populations worldwide ${ }^{(13-16)}$ may generate the need for additional country/region-specific growth reference values.

Although many countries in the South-East Asian region had conducted surveys in the past, it was believed that health and nutritional information, especially in older infants and children, was lacking or no longer up to date. With this background, the South-East Asian Nutrition Survey (SEANUTS) was initiated in 2010. SEANUTS was conducted in large country-representative samples of 0.5- to 12-year-old infants and children in Indonesia, Malaysia, Thailand and Vietnam. The study aimed to provide insights into the nutritional status, growth, food intake, physical activity and health of the children living in South-East Asia ${ }^{(17)}$.

The objectives of the present study were to: (i) derive length/height percentile values from the SEANUTS population, using equivalent exclusion criteria and following a similar methodological approach as WHO in developing its growth references ${ }^{(18)}$; (ii) examine the appropriateness of pooling SEANUTS data for developing common length/ height percentile values for all SEANUTS countries or using country-specific ones, instead; and (iii) examine whether the pooled SEANUTS length/height percentile values are different from the reference values provided by WHO.

\section{Materials and methods}

\section{Sampling}

The sampling procedures followed in each one of the four SEANUTS countries are described in detail elsewhere ${ }^{(17,19-22)}$. In brief, both Indonesia and Thailand used population-based sampling approaches, whereas Malaysia and Vietnam performed their sampling in nurseries, kindergartens and primary schools. More specifically the surveys conducted in Indonesia and Thailand were household-based, thus resulting in also recruiting children who were not necessarily enrolled in nurseries, kindergartens or primary schools. In addition, the surveys conducted in Malaysia and Vietnam were school-based, i.e. using nurseries, kindergartens and primary schools as 'entry points' for recruiting children and also approaching and collecting data from their parents. Furthermore, Indonesia, Thailand and Vietnam used a multistage cluster sampling approach, while Malaysia used a stratified random sampling approach. Urban and rural areas were taken as strata and the various (sub) regions per country as clustering units. The principal clustering unit was the demographic unit with the highest number of inhabitants. Weight factor calculation was done on the basis of the number of boys and girls per age group defined per regional unit as representative to the total number of children in the next demographic unit and finally to national level. This was done according to the demographic information per country available during the last national census (i.e. in all countries, that of 2010) obtained from the respective National Statistics Centres. The sampling procedures resulted in representative samples of boys and girls from both urban and rural areas in each one of the four SEANUTS countries and consequently in the recruitment of a total number of 16744 infants and children aged 0-12 years. These children were considered apparently healthy since they did not exhibit any sign of physical, clinical mental or clinical genetic disorders at the time of recruitment and were capable of participating in the study. Exclusion criterion for participation was age $<6$ months and $>12$ years (except for Vietnam that used 11 years as an upper age cut-off, since this is the upper age limit for attending primary school in the country). Further to the representativeness achieved at a country level, the study population could also be considered as representative at a regional level, since it reflected the distribution of children in the four SEANUTS countries. In this context, the higher number of study participants from Indonesia reflected the larger population of Indonesian children aged 0-14 years, according to demographic data derived from the national census of 2010 as well as from the World Bank for the years of 2010 and $2011^{(23)}$.

\section{Power analysis}

The number of participants included in each of the four countries was based on the potential occurrence of underweight (9.0-18.4\%). More information on the algorithm used for the power analysis and sample size calculation in the present study is provided elsewhere ${ }^{(17,19-22)}$.

\section{Data collection}

The methodological procedures followed for data collection were standardized when feasible, thus facilitating 
comparison of results among countries. The present study is registered in the Netherlands Trial Registry as NTR2462.

Each of the countries used mobile field teams to visit the regions randomly selected to be included in the study. Each team consisted of researchers with knowledge of nutrition and/or biomedical analysis. All research team members were centrally trained on the objectives of the study, sampling procedures, anthropometric measurements, clinical examinations, interviewing techniques, sequence of questionnaires and their variables, field management and, at a later stage, data entry and 'cleaning'.

\section{Length and height measurements}

Height was measured using a stadiometer or microtoise to the nearest $0 \cdot 1 \mathrm{~cm}$. For height measurements, children were measured standing straight and barefooted, with their heels (together), shoulder, back and buttocks touching the wall and head aligned to the Frankfurt horizontal plane. In children aged below 2 years, recumbent length was measured to the nearest $0.1 \mathrm{~cm}$ using a length board.

Sociodemographic background and general health status Sociodemographic data, including the level of parental education and income, as well as health status data were collected via a set of questionnaires that were filled in with information provided by parents and children. All questionnaires were interviewer- or self- (parents) administered. For children aged 6 months to 9 years the interviews were conducted with their parents or caregivers, while for children aged 10 years and older the interviews were conducted with both children and their parents.

\section{Data processing and exclusion criteria}

Following the collection of data, data entry was done using specially developed programs (Indonesia and Thailand), Epi Info (Malaysia) and EpiData $3 \cdot 1$ (Vietnam).
In addition, Excel files with a fixed format were used by all countries for the final overview of data. At least $10 \%$ of data had a double entry made by different persons to check the accuracy of data entry. Excel files, statistical data files and other information related to the study were uploaded to a specially secured SEANUTS website on a regular basis where all data were accessible for the project team and per country for the specific research teams.

At regular time intervals, these data tables were cleaned and checked for obvious outliers, typing errors and missing data using specific tools within STATA version 12, PASW Statistics version 18 and Excel. Accordingly, missing values have been coded and are not included in the final evaluation. Outliers were checked for potential effects on the various population-based results and discussed with the representatives per country. The various descriptive values are all weighted for population size/distribution, and mean values have been tested for differences after correction for age and/or area of residence where appropriate.

In order to make SEANUTS data as comparable as possible to the anthropometric indices collected in the MGRS, the exclusion/inclusion criteria applied in the latter study (namely 'children's health status', 'maternal educational level' and 'family income') were also used (up to the extent this was applicable) in the case of SEANUTS (Table 1). Regarding the exclusion criteria of 'children's health status' and 'maternal educational level', these were used to identify eligible children in all participating countries. Concerning 'family income', this was not used as an exclusion criterion only in the case of Vietnam due to non-availability of these data for approximately $31 \%$ of the population under study. In addition, in the case of Indonesia, instead of income a proxy socioeconomic status (SES) score was used (i.e. combining data on household expenditures for food and non-food items, housing condition and household valuable goods). This is

Table 1 Exclusion criteria applied to identify eligible subjects in the total SEANUTS sample and in each individual country

\begin{tabular}{|c|c|}
\hline Exclusion criterion & Description \\
\hline $\begin{array}{l}\text { 1. Children's health } \\
\text { status }\end{array}$ & $\begin{array}{l}\text { Children from Malaysia, Thailand and Vietnam (data were available for children up to the age of } 6 \text { years) having any } \\
\text { of the following diseases were excluded: heart disease, diabetes, seizures/epilepsy, physical handicap and genetic } \\
\text { disease } \\
\text { Children from Indonesia having any of the following disease were excluded: typhoid fever, malaria, tuberculosis, } \\
\text { haemorrhagic fever or any other kind of serious fever within the last } 12 \text { months }\end{array}$ \\
\hline 2. Maternal education & Children with illiterate mothers (i.e. mothers with ‘no schooling’) were excluded \\
\hline 3. Family income & $\begin{array}{l}\text { Thailand: children whose families had a monthly household income below } 2422 \text { Baht per family member were } \\
\text { excluded } \\
\text { Malaysia: children whose families had a monthly household income below } 720 \text { RM were excluded } \\
\text { Indonesia: while in the other three SEANUTS countries data were collected on income, a proxy of family income was } \\
\text { used based on housing condition and valuable goods owned by the family, similar to the methods also used by the } \\
\text { Indonesian Central Bureau of Statistics. Specifically, a continuous SES score was calculated by scoring the } \\
\text { variables of housing condition and goods and by summing them up. The total SES score was divided into deciles } \\
\text { (i.e. } 1-10 \text { ) and children in the first decile (i.e. the poorest) were excluded } \\
\text { Vietnam: The 'family income' criterion was not used in the case of Vietnam, since this information was not available } \\
\text { for } \sim 31 \% \text { of the population under study }\end{array}$ \\
\hline
\end{tabular}

SEANUTS, South-East Asian Nutrition Survey; SES, socio-economic status. 
a common approach for assessing SES in Indonesia, dictated by the Indonesian Central Bureau of Statistics ${ }^{(24)}$. This is because family income is not considered to be a valid index of SES in Indonesia because there are income sources additional to the take-home salary coming from formal employment; for example, there might be also a daily or monthly income coming from occasional employment. The poverty threshold in Indonesia is set at the first decile of the SES score. In Thailand, the poverty threshold is set at 2422 Baht per family member per month as proposed by the National Economic and Social Development Board of Thailand ${ }^{(25)}$. In Malaysia the poverty threshold is set at $720 \mathrm{RM}$ per month according to the Malaysian Department of Statistics ${ }^{(26)}$. After applying the aforementioned exclusion criteria, a final total pooled SEANUTS sample of 14202 children with full data on length/height, age and sex was used in the current analyses (Table 2). Those children excluded (i.e. $n$ 2364) were almost consistently found to have significantly lower levels of height/length per year of age in all age groups from 1 to 10 years, compared with those children who were not excluded (data not shown). This indicates that the criteria used to exclude children in the current study could be considered valid enough in identifying and thus excluding those with possible health and/or socio-economic constraints on their growth.

\section{Statistical analysis}

Smoothing methods

Cole and Green's LMS method ${ }^{(27)}$, which summarizes the distribution of data by sex and age in terms of three spline curves called L, M and S (i.e. the Box-Cox transformation power that converts data to normality and minimizes the skewness of the data set (L), the median (M) and the coefficient of variation (S)), was used to calculate percentile (P) values. More specifically, the software LMSChartMaker version 2.54 was used to extract the 'smoothed' percentile values at P3, P5, P50, P95 and P97 for body length/height by sex and age. As the LMSChartMaker software also provides the feature/setting of using transformed age for complex $M$ curves that rise and fall at different age intervals, age was log-transformed in the current study to obtain a better fit during age intervals of faster or slower growth velocities. For achieving an optimal fit and determining the amount of smoothness of the curves, the number of the 'equivalent degrees of freedom' was used. After achieving an optimal fit, the distribution of age was rescaled back to original age. Lastly, in order to also adjust for unequal sample sizes in the four sites and avoid over-representation of Indonesia, the samples of Malaysia, Thailand and Vietnam were weighted before extracting the 'smoothed' length/height percentile values using a weight factor of ' 2 ', thus achieving approximately equal sample sizes in all sites.

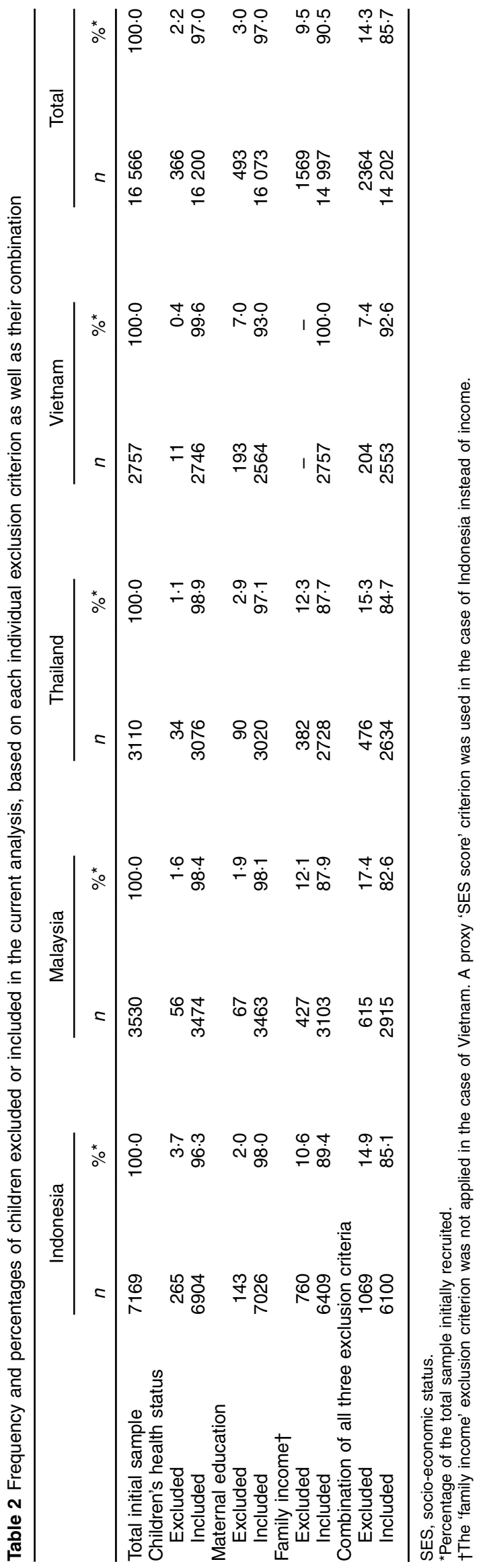




\section{Assessment of length/height differences}

The current study assessed the differences in the 'smoothed' length/height percentile values by age groups in two ways: (i) between the pooled SEANUTS sample and the remaining pooled SEANUTS samples after excluding single 'sites', which refers to countries in the SEANUTS; and (ii) between WHO and the pooled SEANUTS sample. Differences in 'smoothed' length/height-for-age percentile values were expressed relative to the SD of the WHO and the all-sites pooled SEANUTS sample, respectively. For example, for comparing WHO with pooled SEANUTS data, the 'standardized site effects' (SSE) were calculated, indicating the differences between WHO and pooled SEANUTS percentile values divided by the WHO SD. As an example, the following formula was used for the calculation of the SSE for the third percentile:

$$
\operatorname{SSE}(\mathrm{P} 3)=\frac{\mathrm{P} 3(\text { pooled SEANUTS })-\mathrm{P} 3(\mathrm{WHO})}{\mathrm{SD}(\text { mean } / \mathrm{P} 50)} .
$$

The same approach was used when comparing pooled SEANUTS percentile values with the corresponding percentile values for the remaining pooled SEANUTS sample after excluding single sites. The magnitude and consistency of the observed differences, based on the calculated SSE values, were used to examine the two main objectives of the present study. In this context, absolute SSE differences of $\geq 0$ to $<0 \cdot 2$ are considered small, $\geq 0 \cdot 2$ to $<0.5$ are considered medium, and $\geq 0.5$ are considered large ${ }^{(28)}$. Similar to the approach also followed in the WHO MGRS study ${ }^{(29)}$, |SSE | were acceptable if these were $<0.5$.

\section{Results}

The LMS values of the length/height distributions are presented in the online supplementary material, Supplemental Table 1 for boys and girls of the pooled SEANUTS sample. The distributions of length/height in boys were not symmetrical (i.e. $\mathrm{L}=1$ ) since in the ages from 1 to 9 years the values of $\mathrm{L}$ were higher than 1 , indicating skewness to the left, while in the age groups of 0.5 and 10 to 12 years the $\mathrm{L}$ values were lower than 1 , indicating skewness to the right. Similarly, non-symmetrical distributions were also observed for length/height in girls, since all values of $\mathrm{L}$ in the ages from 0.5 to 10 years were lower than 1, while in the age groups of 11 and 12 years the $\mathrm{L}$ values were higher than 1 .

In line with the first objective of the current study (i.e. deriving growth percentile values from the SEANUTS population), Supplemental Tables 2 and 3 in the online supplementary material present the length/height-for-age percentile values (i.e. at P3, P5, P50, P95 and P97) in the age groups of 0.5 to 12 years, for boys and girls, respectively. A summary of the above data, for specific percentiles (i.e. P3, P50 and P97) and age groups for boys and girls, is presented in Table 3. In the context of the second objective of the current study (i.e. to examine the appropriateness of using pooled SEANUTS data instead of country-specific ones), these same tables present the pair-wise comparisons of length/height-for-age percentile values between the pooled SEANUTS sample (i.e. including data from all four countries) and the remaining pooled SEANUTS samples after excluding the data from each country. Although absolute values of SSE that are higher than 0.5 indicate large (i.e. unacceptable) differences and potential inappropriateness of using pooled SEANUTS instead of country-specific data, only a few large differences were observed. More specifically, only eight large differences in length/height percentile values were observed in boys when excluding data from Indonesia. These differences were observed at the lower percentiles (i.e. P3, P5) for the age groups of 1 to 4 years (Table 3 and Supplemental Table 2). In girls, only five large differences were observed at the lower percentiles (i.e. P3, P5) for the age groups of 1.5 to 3 years when excluding data from Indonesia (Table 3 and Supplemental Table 3).

As far as the third and last objective of the current study is concerned (i.e. to examine the differences between pooled SEANUTS and WHO data), Supplemental Tables 4 and 5 (as well as Supplemental Figs 1 and 2) in the online supplementary material present for boys and girls respectively the length/height-for age percentile values (i.e. at P3, P5, P50, P95 and P97) for the age groups of 0.5 to 12 years and the SSE values for these comparisons. A summary of the above data, for specific percentiles (i.e. P3, P50 and P97) and age groups for boys and girls, is presented in Table 4. Out of a total of seventy comparisons between pooled SEANUTS and WHO data, fifty-two large differences were observed for boys and girls, respectively. The vast majority of these were negative and were observed in the lower and median percentiles (i.e. P3, P5 and P50) in almost all age groups and both sexes. In the upper percentiles (i.e. P95, P97) there were five positive large differences observed in both sexes for the age groups of 0.5 and 1 years, while all other large differences were negative and observed in the age groups of 1.5 to 9 years (Table 4 as well as Supplemental Tables 4 and 5 , respectively).

\section{Discussion}

The SEANUTS study is a large-scale epidemiological survey conducted in country-representative samples of 0.5- to 12-year-old children from Indonesia, Malaysia, Thailand and Vietnam. With respect to its first objective, i.e. deriving length/height percentile values from the SEANUTS population, the present study employed certain exclusion criteria for identifying eligible children which were as similar as possible (based on data availability) to the ones used by WHO in the MGRS ${ }^{(18)}$. Following this 
Table 3 Pair-wise comparisons of the median (P50), third (P3) and ninety-seventh (P97) percentile values for length/height in boys and girls between the pooled SEANUTS sample and the remaining pooled SEANUTS sample after excluding single sites

\begin{tabular}{|c|c|c|c|c|c|c|c|c|c|c|c|c|c|c|}
\hline & \multicolumn{14}{|c|}{ Length/height $(\mathrm{cm})$} \\
\hline & \multicolumn{7}{|c|}{ Boys } & \multicolumn{7}{|c|}{ Girls } \\
\hline & \multicolumn{3}{|c|}{ P50 } & \multicolumn{2}{|c|}{ P3 } & \multicolumn{2}{|c|}{ P97 } & \multicolumn{3}{|c|}{ P50 } & \multicolumn{2}{|c|}{ P3 } & \multicolumn{2}{|c|}{ P97 } \\
\hline & Mean & SD & SSE & Mean & SSE & Mean & SSE & Mean & SD & SSE & Mean & SSE & Mean & SSE \\
\hline \multicolumn{15}{|l|}{6 months } \\
\hline $\begin{array}{l}\text { Pooled SEANUTS } \\
\text { Excluding: }\end{array}$ & $68 \cdot 1$ & $3 \cdot 6$ & 0.00 & $61 \cdot 3$ & 0.00 & $75 \cdot 0$ & 0.00 & $65 \cdot 9$ & 3.0 & 0.00 & $60 \cdot 6$ & 0.00 & $71 \cdot 8$ & 0.00 \\
\hline Malaysia & 68.2 & 3.7 & 0.04 & $61 \cdot 4$ & 0.03 & $75 \cdot 2$ & 0.05 & $65 \cdot 7$ & 3.0 & -0.06 & $60 \cdot 4$ & -0.05 & 71.7 & -0.02 \\
\hline Thailand & 68.2 & 3.7 & 0.01 & 61.5 & 0.05 & 75.4 & 0.12 & 65.9 & 3.0 & 0.01 & 60.6 & 0.03 & 72.0 & 0.09 \\
\hline Indonesia & 67.8 & 2.8 & -0.09 & 62.9 & 0.43 & 73.4 & -0.43 & 65.4 & 2.5 & -0.14 & $61 \cdot 1$ & 0.17 & 70.5 & -0.43 \\
\hline Vietnam & 68.0 & 3.7 & -0.03 & 61.2 & -0.03 & $75 \cdot 2$ & 0.06 & 65.8 & 3.0 & -0.02 & 60.4 & -0.06 & 71.7 & -0.01 \\
\hline \multicolumn{15}{|l|}{2 years } \\
\hline $\begin{array}{l}\text { Pooled SEANUTS } \\
\text { Excluding: }\end{array}$ & $84 \cdot 0$ & 4.4 & 0.00 & $75 \cdot 3$ & 0.00 & $92 \cdot 0$ & 0.00 & $82 \cdot 6$ & $4 \cdot 0$ & 0.00 & $75 \cdot 4$ & 0.00 & $90 \cdot 3$ & 0.00 \\
\hline Malaysia & $84 \cdot 1$ & 4.5 & 0.00 & 74.0 & -0.28 & 92.2 & 0.04 & 82.5 & 4.1 & -0.02 & $75 \cdot 1$ & -0.06 & 90.4 & \\
\hline Thailand & 83.4 & 4.5 & -0.14 & 74.7 & -0.12 & 91.6 & -0.08 & $82 \cdot 0$ & 4.0 & -0.13 & 74.9 & -0.12 & 90.1 & -0.06 \\
\hline Indonesia & 85.0 & 3.7 & 0.21 & $78 \cdot 3$ & 0.68 & 92.1 & 0.03 & 83.8 & 3.5 & 0.30 & 77.6 & 0.56 & 90.7 & 0.10 \\
\hline Vietnam & 83.8 & 4.5 & -0.06 & 75.0 & -0.05 & 91.9 & -0.02 & 82.4 & 4.0 & -0.05 & 75.0 & -0.08 & 90.1 & -0.04 \\
\hline \multicolumn{15}{|l|}{4 years } \\
\hline $\begin{array}{l}\text { Pooled SEANUTS } \\
\text { Excluding: }\end{array}$ & $99 \cdot 9$ & $5 \cdot 2$ & 0.00 & $89 \cdot 4$ & 0.00 & $109 \cdot 0$ & 0.00 & $98 \cdot 7$ & $5 \cdot 0$ & 0.00 & 89.5 & 0.00 & $108 \cdot 4$ & 0.00 \\
\hline Malaysia & 99.6 & 5.4 & -0.06 & 88.6 & -0.15 & 109.0 & -0.01 & 98.2 & $5 \cdot 1$ & -0.08 & 88.9 & -0.12 & $108 \cdot 2$ & -0.05 \\
\hline Thailand & 99.1 & 5.3 & -0.14 & 88.6 & -0.16 & 108.6 & -0.09 & 97.9 & $5 \cdot 1$ & -0.15 & 88.8 & -0.15 & 108.0 & -0.08 \\
\hline Indonesia & 101.0 & 4.6 & 0.22 & 92.2 & 0.55 & 109.5 & 0.09 & 99.9 & 4.5 & 0.25 & 91.7 & 0.43 & 108.7 & 0.06 \\
\hline Vietnam & 99.6 & $5 \cdot 2$ & -0.04 & 89.4 & 0.01 & 108.9 & -0.02 & 98.6 & $5 \cdot 1$ & -0.02 & 89.4 & -0.03 & $108 \cdot 4$ & 0.00 \\
\hline \multicolumn{15}{|l|}{6 years } \\
\hline $\begin{array}{l}\text { Pooled SEANUTS } \\
\text { Excluding: }\end{array}$ & $112 \cdot 6$ & $5 \cdot 8$ & 0.00 & 101.1 & 0.00 & $123 \cdot 0$ & 0.00 & 111.4 & $5 \cdot 8$ & 0.00 & $100 \cdot 7$ & 0.00 & $122 \cdot 7$ & 0.00 \\
\hline Malaysia & $112 \cdot 0$ & 6.0 & -0.10 & $100 \cdot 0$ & -0.18 & $122 \cdot 7$ & -0.04 & $110 \cdot 9$ & 5.9 & -0.08 & $100 \cdot 1$ & -0.10 & $122 \cdot 4$ & -0.05 \\
\hline Thailand & 112.2 & 6.0 & -0.06 & 100.4 & -0.11 & $122 \cdot 9$ & 0.00 & 110.8 & $6 \cdot 0$ & -0.10 & 100.1 & -0.11 & $122 \cdot 6$ & -0.02 \\
\hline Indonesia & 113.5 & 5.4 & 0.16 & 103.0 & 0.35 & 123.3 & 0.05 & 112.4 & 5.4 & 0.18 & 102.5 & 0.31 & 122.8 & 0.02 \\
\hline Vietnam & $112 \cdot 4$ & 5.7 & -0.03 & $101 \cdot 3$ & 0.04 & $122 \cdot 8$ & -0.03 & 111.2 & $5 \cdot 9$ & -0.02 & 100.6 & -0.03 & $122 \cdot 6$ & 0.00 \\
\hline \multicolumn{15}{|l|}{8 years } \\
\hline Pooled SEANUTS & 123.6 & $6 \cdot 4$ & 0.00 & 111.2 & 0.00 & 135.5 & 0.00 & $122 \cdot 9$ & 6.6 & 0.00 & $110 \cdot 8$ & 0.00 & 135.5 & 0.00 \\
\hline $\begin{array}{l}\text { Excluding: } \\
\text { Malaysia }\end{array}$ & 122.9 & & & & & & & & & & & & & \\
\hline $\begin{array}{l}\text { Malaysia } \\
\text { Thailand }\end{array}$ & 123.3 & $\begin{array}{l}6 \cdot 6 \\
6 \cdot 6\end{array}$ & $\begin{array}{l}-0.11 \\
-0.04\end{array}$ & $\begin{array}{l}110 \cdot 2 \\
110.7\end{array}$ & $\begin{array}{l}-0.15 \\
-0.08\end{array}$ & $\begin{array}{l}135 \cdot 2 \\
135 \cdot 6\end{array}$ & $\begin{array}{r}-0.04 \\
0.02\end{array}$ & $\begin{array}{l}122 \cdot 3 \\
122.4\end{array}$ & $\begin{array}{l}6.6 \\
6.7\end{array}$ & $\begin{array}{l}-0.09 \\
-0.07\end{array}$ & $\begin{array}{l}110 \cdot 2 \\
110.2\end{array}$ & $\begin{array}{l}-0.09 \\
-0.08\end{array}$ & $\begin{array}{l}135 \cdot 1 \\
135 \cdot 6\end{array}$ & -0.06 \\
\hline Indonesia & 124.4 & $\begin{array}{l}0.0 \\
6.1\end{array}$ & $\begin{array}{r}-0.04 \\
0.14\end{array}$ & $112 \cdot 7$ & $\begin{array}{r}-0.00 \\
0.24\end{array}$ & $135 \cdot 7$ & 0.04 & $124 \cdot 0$ & $\begin{array}{l}0.1 \\
6.2\end{array}$ & $\begin{array}{r}-0.01 \\
0.17\end{array}$ & $112 \cdot 5$ & $\begin{array}{r}-0.00 \\
0.26\end{array}$ & 135.8 & 0.05 \\
\hline Vietnam & 123.4 & $6 \cdot 3$ & -0.02 & 111.5 & 0.05 & $135 \cdot 2$ & -0.04 & $122 \cdot 8$ & $6 \cdot 6$ & -0.01 & 110.6 & -0.03 & 135.5 & 0.00 \\
\hline \multicolumn{15}{|l|}{10 years } \\
\hline $\begin{array}{l}\text { Pooled SEANUTS } \\
\text { Excluding: }\end{array}$ & $133 \cdot 8$ & $7 \cdot 2$ & 0.00 & $120 \cdot 5$ & 0.00 & 147.5 & 0.00 & $134 \cdot 7$ & $7 \cdot 3$ & 0.00 & $121 \cdot 0$ & 0.00 & $148 \cdot 6$ & 0.00 \\
\hline Malaysia & $132 \cdot 9$ & $7 \cdot 3$ & -0.13 & 119.5 & -0.14 & $147 \cdot 1$ & -0.06 & 133.7 & 7.4 & -0.13 & 120.1 & -0.12 & 147.8 & -0.10 \\
\hline Thailand & 133.4 & 7.4 & -0.05 & 119.8 & -0.09 & 147.5 & 0.00 & 134.3 & 7.5 & -0.06 & 120.4 & -0.08 & 148.6 & 0.00 \\
\hline Indonesia & 134.7 & 6.9 & 0.12 & 121.8 & 0.18 & 147.9 & 0.05 & $135 \cdot 7$ & $7 \cdot 0$ & 0.14 & $122 \cdot 7$ & 0.23 & $149 \cdot 0$ & 0.06 \\
\hline Vietnam & 134.0 & 7.0 & 0.02 & 121.0 & 0.07 & 147.4 & -0.01 & 134.9 & 7.4 & 0.02 & 120.9 & -0.01 & 148.6 & 0.01 \\
\hline
\end{tabular}


Table 4 Comparisons of the median (P50), third (P3) and ninety-seventh (P97) percentile values for length/height in boys and girls between WHO and pooled SEANUTS samples

\begin{tabular}{|c|c|c|c|c|c|c|c|c|c|c|c|c|c|c|}
\hline & \multicolumn{14}{|c|}{ Length/height $(\mathrm{cm})$} \\
\hline & \multicolumn{7}{|c|}{ Boys } & \multicolumn{7}{|c|}{ Girls } \\
\hline & \multicolumn{3}{|c|}{ P50 } & \multicolumn{2}{|c|}{ P3 } & \multicolumn{2}{|c|}{ P97 } & \multicolumn{3}{|c|}{ P50 } & \multicolumn{2}{|c|}{ P3 } & \multicolumn{2}{|c|}{ P97 } \\
\hline & Mean & SD & SSE & Mean & SSE & Mean & SSE & Mean & SD & SSE & Mean & SSE & Mean & SSE \\
\hline \multicolumn{15}{|l|}{6 months } \\
\hline WHO & $67 \cdot 6$ & $2 \cdot 1$ & 0.00 & 63.6 & 0.00 & 71.6 & 0.00 & $65 \cdot 7$ & $2 \cdot 3$ & 0.00 & 61.5 & 0.00 & $70 \cdot 0$ & 0.00 \\
\hline Pooled SEANUTS & $68 \cdot 1$ & 3.6 & 0.22 & $61 \cdot 3$ & -1.07 & $5 \cdot 0$ & $1 \cdot 57$ & $65 \cdot 9$ & 3.0 & 0.05 & 60.6 & -0.42 & $71 \cdot 8$ & 0.77 \\
\hline \multicolumn{15}{|l|}{2 years } \\
\hline WHO & 87.8 & 3.1 & 0.00 & $82 \cdot 1$ & 0.00 & 93.6 & 0.00 & $86 \cdot 4$ & 3.2 & 0.00 & $80 \cdot 3$ & 0.00 & 92.5 & 0.00 \\
\hline Pooled SEANUTS & 84.0 & $4 \cdot 4$ & $-1 \cdot 24$ & $75 \cdot 3$ & $-2 \cdot 24$ & $92 \cdot 0$ & -0.53 & 82.6 & 4.0 & $-1 \cdot 20$ & $75 \cdot 4$ & -1.54 & $90 \cdot 3$ & -0.68 \\
\hline \multicolumn{15}{|l|}{4 years } \\
\hline WHO & $103 \cdot 3$ & 4.2 & 0.00 & 95.4 & 0.00 & $111 \cdot 2$ & 0.00 & $102 \cdot 7$ & 4.3 & 0.00 & 94.6 & 0.00 & $110 \cdot 8$ & 0.00 \\
\hline Pooled SEANUTS & 99.9 & $5 \cdot 2$ & -0.83 & 89.4 & $-1 \cdot 43$ & 109.0 & -0.52 & 98.7 & $5 \cdot 0$ & -0.95 & 89.5 & $-1 \cdot 18$ & 108.4 & -0.56 \\
\hline \multicolumn{15}{|l|}{6 years } \\
\hline WHO & $116 \cdot 0$ & 4.9 & 0.00 & $106 \cdot 7$ & 0.00 & $125 \cdot 2$ & 0.00 & $115 \cdot 1$ & $5 \cdot 1$ & 0.00 & $105 \cdot 5$ & 0.00 & 124.8 & 0.00 \\
\hline Pooled SEANUTS & 112.6 & $5 \cdot 8$ & -0.69 & $101 \cdot 1$ & $-1 \cdot 15$ & 123.0 & -0.45 & 111.4 & $5 \cdot 8$ & -0.74 & $100 \cdot 7$ & -0.94 & $122 \cdot 7$ & -0.42 \\
\hline \multicolumn{15}{|l|}{8 years } \\
\hline WHO & $127 \cdot 3$ & 5.7 & 0.00 & $116 \cdot 6$ & 0.00 & 137.9 & 0.00 & $126 \cdot 6$ & $5 \cdot 8$ & 0.00 & $115 \cdot 7$ & 0.00 & 137.5 & 0.00 \\
\hline Pooled SEANUTS & 123.6 & $6 \cdot 4$ & -0.66 & 111.2 & -0.96 & 135.5 & -0.43 & 122.9 & 6.6 & -0.64 & $110 \cdot 8$ & -0.85 & 135.5 & -0.34 \\
\hline \multicolumn{15}{|l|}{10 years } \\
\hline WHO & 137.8 & $6 \cdot 4$ & 0.00 & 125.8 & 0.00 & 149.8 & 0.00 & $138 \cdot 6$ & $6 \cdot 4$ & 0.00 & $126 \cdot 6$ & 0.00 & $150 \cdot 7$ & 0.00 \\
\hline Pooled SEANUTS & 133.8 & $7 \cdot 2$ & -0.62 & $120 \cdot 5$ & -0.83 & 147.5 & -0.36 & $134 \cdot 7$ & $7 \cdot 3$ & -0.61 & 121.0 & -0.88 & $148 \cdot 6$ & -0.34 \\
\hline
\end{tabular}

SEANUTS, SEANUTS, South-East Asian Nutrition Survey; SSE, standardized site effect (difference between WHO mean and the corresponding pooled SEANUTS mean divided by the WHO sD).

SSE marked in bold font correspond to values greater than 0.5 or lower than -0.5 . 
procedure a total sample of 14202 eligible infants and children were included in the present analyses for deriving the length/height percentile values from SEANUTS. Considering the age range of children in SEANUTS (i.e. 0.5 to 12 years old), this final sample size is comparable to the sample sizes of the MGRS (i.e. 8440 infants and children 0-6 years old $)^{(7)}$ and the National Center for Health Statistics (i.e. 22917 children and adolescents 5-19 years old ${ }^{(8)}$ used to construct the current WHO growth references.

Regarding the second objective, i.e. examining whether it is more appropriate to use the pooled SEANUTS data for calculating common length/height percentile values for all SEANUTS countries instead of country-specific ones, the few large differences observed among individual SEANUTS countries and the pooled SEANUTS sample are supporting the appropriateness of using pooled SEANUTS data. These differences were observed in the lower percentiles (i.e. P3 and P5), for the age groups of 1 to 4 years and primarily when excluding Indonesia from the total sample, indicating that the Indonesian sample tended to coincide most closely to the pooled SEANUTS sample percentile values. In addition, the consistent positive SSE values observed indicate that children from Indonesia below the age of 5 years have lower length/height values at P3 and P5 compared with the other three countries. Nevertheless, out of a total number of 280 comparisons (i.e. fourteen age time points, five percentiles and four SEANUTS countries) conducted for each sex, the vast majority of inter-site differences were relatively small indicating comparable length/height percentile values between pooled SEANUTS and individual countries (see Supplemental Tables 2 and 3 in the online supplementary material).

The procedures followed by the present study to examine its objectives are similar to those previously followed by WHO in the MGRS ${ }^{(29)}$. The findings of the present study are in line with those reported by WHO when assessing differences in body length/height percentile values among the different participating populations/countries ${ }^{(29)}$. In their article, the WHO MGRS Group reported that the variability in length/height percentile values was due primarily to inter-individual differences rather than to differences among sites. Since approximately $90 \%$ of the total genetic variability resides within populations while only $10-15 \%$ is across populations ${ }^{(30)}$, the WHO authors further argue that it is unlikely for growth indices, such as stature, to differ significantly among large non-isolated population groups ${ }^{(31)}$ and that the relatively small differences among sites observed in the MGRS was rather expected and might decrease further in future studies. Up to a certain degree the findings derived from SEANUTS data in the current study are supportive to the aforementioned argument made by the WHO MGRS Group, as the vast majority of inter-site differences in length/height percentile values were quite small.
The third objective of the present study was to examine whether the length/height percentile values developed from the pooled SEANUTS data were different from the corresponding ones provided by $\mathrm{WHO}^{(7)}$. The results derived from these comparisons between pooled SEANUTS and WHO length/height percentile values show that the data differ. Specifically, these comparisons revealed that length/height values were consistently lower in the pooled SEANUTS sample compared with WHO in almost all ages and percentiles in both sexes. The differences observed in the current study between WHO and SEANUTS percentile values should be kept in mind when using WHO growth curves to assess length/height in these South-East Asian populations. The findings of the current study could reflect actual differences at a population level between the pooled SEANUTS and WHO length/height percentile values. Following this reasoning, the lower (compared with WHO) length/height values that were almost consistently observed in both sexes, all ages and percentiles examined in the current study are in line with the available literature reporting lower stature for South Asian populations compared with populations on other continents ${ }^{(32)}$ and indicating that shorter length/ height is very likely to be the actual phenotype for South Asian populations ${ }^{(12)}$.

However, the large differences between pooled SEANUTS and WHO data for almost all ages and percentiles could also be due to certain limitations of the present study such as the ones listed below. First, although the majority of exclusion criteria applied in the present study were similar to those used by WHO in the MGRS, the application of all exclusion criteria was not feasible. Specifically, although the rates of exclusive breast-feeding (up to 6 months of age) have been reported to range from $15 \cdot 1 \%$ in Thailand to $41.5 \%$ in Indonesia ${ }^{(14,33)}$, the 'breastfeeding criterion' could not be used since this information was available for only a small sub-sample of the total SEANUTS sample. Non-availability of data also applied for other potential perinatal constraints on growth (e.g. premature birth and low birth weight), since these data were either not collected in the four SEANUTS countries or collected retrospectively for only a small sub-sample of younger (i.e. $<2$ years old) children. Regarding limitations in applying the rest of the exclusion criteria, the 'family income' criterion was not used in the case of Vietnam as these data were not available for approximately $31 \%$ of the total sample. However, in all age groups mean length/height values were consistently found to be lower in children excluded from the current analyses (i.e. $n$ 2364) compared with children included in the analyses (i.e. $n 14202$; data not shown). This probably indicates that the exclusion criteria applied in the current study were valid enough in identifying children with health and/or socio-economic constraints on their growth. Further to the limitations stemming from the application of the 'exclusion criteria', the school-based sampling in 
Malaysia and Vietnam could probably have resulted in non-inclusion of eligible children who were not enrolled in nurseries, kindergartens and primary schools. Furthermore, non-availability of blood samples/data for the total SEANUTS population could be considered another limitation, since children with anaemia and/or other micronutrient deficiencies negatively affecting growth could not be detected and consequently excluded from the current analyses. Lastly, despite the existence and use by other studies of alternative statistical methods to examine differences in percentile values ${ }^{(11,12)}$, the current study used SSE, thus following the same approach as WHO in assessing differences in linear growth in the $\operatorname{MGRS}^{(29)}$.

\section{Conclusion}

In conclusion, the current study developed length/height percentile values for infants and children aged 0.5 to 12 years from four South-East Asian countries and was supportive of the appropriateness of using pooled SEANUTS percentile values for assessing children's length/ height in all four countries. The length/height percentile values developed in the present study were found to differ from the ones provided by WHO. Additional research initiatives should be considered for proposing appropriate length/height cut-off points for assessing linear growth in South-East Asian children and adolescents.

\section{Acknowledgements}

Acknowledgements: The authors are indebted to the research team members of the SEANUTS Study Group, as well as to the parents/carers, infants and children for their willingness to participate in the study. The SEANUTS Study Group comprises the following. Thailand: Nipa Rojroongwasinkul, Atitada Boonpraderm, Pattanee Winichagoon, Petcharat Kunaphan, Uruwan Yamborisut, Wanphen Wimonpeerapattana, Sayamon Senaprom, Kallaya Kijboonchoo, Wiyada Thasanasuwan, Weerachat Srichan, Kusol Soonthorndhada, Sasiumphai Purttiponthanee. Vietnam: Khanh Le Nguyen Bao, Chinh Nguyen Huu, Hop Le Thi, Truong Nguyen Hong, Van Anh Nguyen Đo, Đo Tran Thanh, Nga Tran Thuy, Nhung Bui Thi, Dzung Nguyen Đinh, Tuoc Bui Van, Khang Nguyen Van, Dzung Nguyen Viet, Luan Nguyen Viet, Ha Nguyen Thu Ha, Xuyen Hoang Thi, Long Nguyen Van, Hai Tran Thi, Long Pham Si, Huong Nguyen Thi, Ngan Nguyen Thi, Thao Le Thanh, Kieu Dau Thi, Thang Dinh Tat, Mai Nguyen Thi Tuyet. Indonesia: Sandjaja, Basuki Budiman, Moesijanti Soekatri, Heryudarini Harahap, Fitrah Ernawati, Yekti Widodo, Edith Sumedi, Nurmeida S. Syarief, Rustan Effendi, Gustina Sofia, Minarto, Hidayat Syarief. Malaysia: Poh Bee Koon, Norimah A Karim, Ruzita A Talib, Siti Balkis Budin, Alvin Ng Lai Oon,
Siti Haslinda Mohd Din, Wong Jyh Eiin, Mohd Ismail Noor, Rahman Jamal, Nor Azmi Kamaruddin, Nik Shanita Safii, Chin Yit Siew, Wee Bee Suan, Nor Aini Jamil A. Wahab. FrieslandCampina: Ilse Khouw, Panam Parikh, Swee Ai $\mathrm{Ng}$, Anne Schaafsma, Marjolijn Bragt. Financial support: SEANUTS was supported with a research grant from FrieslandCampina. FrieslandCampina was not involved in the recruitment of participants and the final set of results. Conflict of interest: None of the authors or the research institutes has any conflicts of interest. Any opinions, findings, conclusions or recommendations expressed in this publication are those of the authors and do not necessarily reflect the views of FrieslandCampina. Authorship: N.R., K.L.N.B., S., B.K.P., A.B., C.N.H., M.S. and J.E.W. contributed to the design of the study, data collection and data management. P.D. was involved in study monitoring, data management and data evaluation. Y.M. led the statistical analyses with the contribution and input from all authors. All authors contributed to the writing of the manuscript, critically reviewed and approved the final version of the manuscript for publication. Ethics of human subject participation: This study was conducted according to the guidelines laid down in the Declaration of Helsinki and all procedures involving human subjects/patients were approved by the Medical Ethical Committees of the participating institutes. Written informed consent was obtained for all subjects by their parents and/or caregivers.

\section{Supplementary material}

To view supplementary material for this article, please visit http://dx.doi.org/10.1017/S1368980015003316

\section{References}

1. Kosulwat V (2002) The nutrition and health transition in Thailand. Public Health Nutr 5, 183-189.

2. Noor MI (2002) The nutrition and health transition in Malaysia. Public Health Nutr 5, 191-195.

3. Shetty PS (2002) Nutrition transition in India. Public Health Nutr 5, 175-182.

4. Zong XN, Li H \& Zhu ZH (2011) Secular trends in height and weight for healthy Han children aged 0-7 years in China, 1975-2005. Am J Hum Biol 23, 209-215.

5. World Health Organization (1990-2014) Global Health Observatory Data Repository. Joint child malnutrition estimates (UNICEF-WHO-WB). Regional prevalence and numbers of stunting, underweight and overweight (1990-2014). http://apps.who.int/gho/data/view.wrapper. nutrition-1-7?lang=en (accessed April 2015).

6. World Health Organization (2013) Global Database on Child Growth and Malnutrition. 2013 Joint child malnutrition estimates - Levels and trends. http://www.who.int/ nutgrowthdb/estimates2013/en/ (accessed April 2015).

7. World Health Organization (2006) WHO Child Growth Standards: Length/Height-for-Age, Weight-for-Age, Weightfor-Length, Weight-for-Height and Body Mass Indexfor-Age: Methods and Development. Geneva: WHO, Department of Nutrition for Health and Development. 
8. de Onis M, Onyango AW, Borghi E et al. (2007) Development of a WHO growth reference for school-aged children and adolescents. Bull World Health Organ 85, 660-667.

9. Zong XN \& Li H (2013) Construction of a new growth references for China based on urban Chinese children: comparison with the WHO growth standards. PLoS One $\mathbf{8}$, e59569.

10. Natale V \& Rajagopalan A (2014) Worldwide variation in human growth and the World Health Organization growth standards: a systematic review. BMJ Open 4, e003735.

11. de Wilde JA, van Dommelen P \& Middelkoop BJ (2013) Appropriate body mass index cut-offs to determine thinness, overweight and obesity in South Asian children in the Netherlands. PLoS One 8, e82822.

12. de Wilde JA, van Dommelen P, van Buuren S et al. (2015) Height of South Asian children in the Netherlands aged 0-20 years: secular trends and comparisons with current Asian Indian, Dutch and WHO references. Ann Hum Biol 42, 38-44.

13. Freedman DS, Khan LK, Serdula MK et al. (2006) Racial and ethnic differences in secular trends for childhood BMI, weight, and height. Obesity (Silver Spring) 14, 301-308.

14. Deaton A (2007) Height, health, and development. Proc Natl Acad Sci U S A 104, 13232-13237.

15. Kuczmarski RJ, Ogden CL, Guo SS et al. (2002) 2000 CDC Growth Charts for the United States: methods and development. Vital Health Stat 11 issue 246, 1-190.

16. Prader A, Largo RH, Molinari L et al. (1989) Physical growth of Swiss children from birth to 20 years of age. First Zurich longitudinal study of growth and development. Helv Paediatr Acta Suppl 52, 1-125.

17. Schaafsma A, Deurenberg P, Calame W et al. (2013) Design of the South East Asian Nutrition Survey (SEANUTS): a fourcountry multistage cluster design study. Br J Nutr 110, Suppl. 3, S2-S10.

18. de Onis M, Garza C, Victora CG et al. (2004) The WHO Multicentre Growth Reference Study: planning, study design, and methodology. Food Nutr Bull 25, 1 Suppl., S15-S26.

19. Le Nguyen BK, Le Thi H, Nguyen Do VA et al. (2013) Double burden of undernutrition and overnutrition in Vietnam in 2011: results of the SEANUTS study in 0.5-11-year-old children. Br J Nutr 110, Suppl. 3, S45-S56.

20. Rojroongwasinkul N, Kijboonchoo K, Wimonpeerapattana W et al. (2013) SEANUTS: the nutritional status and dietary intakes of 0.5-12-year-old Thai children. Br J Nutr 110, Suppl. 3, S36-S44.
21. Poh BK, Ng BK, Siti Haslinda MD et al. (2013) Nutritional status and dietary intakes of children aged 6 months to 12 years: findings of the Nutrition Survey of Malaysian Children (SEANUTS Malaysia). Br J Nutr 110, Suppl. 3, S21-S35.

22. Sandjaja S, Budiman B, Harahap H et al. (2013) Food consumption and nutritional and biochemical status of 0.5-12year-old Indonesian children: the SEANUTS study. Br J Nutr 110, Suppl. 3, S11-S20.

23. The World Bank (2010, 2011) Countries. http://www. worldbank.org/en/country (accessed April 2015).

24. Abdul Latif Jameel Poverty Action Lab (2008) Indonesia, Central Bureau of Statistics (BPS). http://www.poverty actionlab.org/partners/indonesia-central-bureau-statistics-bps (accessed April 2015).

25. Office of the National Economic and Social Development Board of Thailand (2011) Poverty line by region, 1988-2011. http://social.nesdb.go.th/SocialStat/StatReport_Final.aspx? reportid $=854 \&$ template $=2 \mathrm{R} 1 \mathrm{C} \&$ yeartype $=$ M\&subcatid $=59$ (accessed April 2015).

26. DOS (2007) Household Income Survey Report, Department of Statistics, Malaysia. In Press statement of Sistem Maklumat Kemiskinan Negara (eKasib). Putrajaya: Implementation Coordination Unit, Prime Minister's Department, Malaysia.

27. Cole TJ \& Green PJ (1992) Smoothing reference centile curves: the LMS method and penalized likelihood. Stat Med 11, 1305-1319.

28. Cohen J (1988) Statistical Power Analysis for the Behavioral Sciences, 2nd ed. Hillsdale, NJ: Lawrence Erlbaum Associates.

29. WHO Multicentre Growth Reference Study Group (2006) Assessment of differences in linear growth among populations in the WHO Multicentre Growth Reference Study. Acta Paediatr Suppl 450, 56-65.

30. Jorde LB \& Wooding SP (2004) Genetic variation, classification and 'race'. Nat Genet 36, 11 Suppl., S28-S33.

31. Cooper RS, Kaufman JS \& Ward R (2003) Race and genomics. N Engl J Med 348, 1166-1170.

32. Victora CG, de Onis M, Hallal PC et al. (2010) Worldwide timing of growth faltering: revisiting implications for interventions. Pediatrics 125, e473-e480.

33. Fatimah S Jr, Siti Saadiah HN, Tahir A et al. (2010) Breastfeeding in Malaysia: results of the Third National Health and Morbidity Survey (NHMS III) 2006. Malays J Nutr 16, 195-206. 